\title{
Child defecation behaviour, stool disposal practices, and childhood diarrhoea in Burkina Faso: results from a case-control study
}

\author{
E Traoré, S Cousens, V Curtis, T Mertens, F Tall, A Traoré, B Kanki, I Diallo, \\ A Rochereau, J-P Chiron, F Mégraud
}

\begin{abstract}
Objective - To investigate the association between where young children defecate, where stools are disposed of, and the presence of human stools on the ground in the compound and the rate of hospital admission with diarrhoea.
\end{abstract}

Design - This was a case-control study with two control groups.

Setting - The study took place in BoboDioulasso, the second city of Burkina Faso in West Africa.

Participants - Three groups of children aged 36 months and under, and living in Bobo-Dioulasso were studied. Cases were 757 children admitted to hospital with symptoms of diarrhoea or dysentery. The first control group comprised 757 neighbourhood control children approximately matched on age and date of recruitment, and the second, 631 children admitted to the same hospital without symptoms of diarrhoea or dysentery.

Main results - There was no evidence of any association between where the child was reported to defecate and hospital admission with diarrhoea or dysentery (odds ratio $=1 \cdot 10 ; 95 \%$ confidence interval $(C I) \quad 0 \cdot 78,1 \cdot 57$, cases $v$ neighbourhood controls; odds ratio $=0.84 ; 95 \%$ CI $0 \cdot 60,1 \cdot 18$, cases $v$ hospital controls). There was evidence of an association between where the mother reported disposing of the child's stools and hospital admission with diarrhoea or dysentery (odds ratio $=1 \cdot 50 ; 95 \%$ CI $1 \cdot 09,2 \cdot 06$, cases $v$ neighbourhood controls; odds ratio $=$ $1 \cdot 31 ; 95 \%$ CI $0 \cdot 96,1 \cdot 79$, cases $v$ hospital controls). Human stools were more frequently observed in the yards of cases than controls (odds ratio $=1 \cdot 38 ; 95 \% \mathrm{CI}$ $0.98,1.95$, cases compared with neighbourhood controls; odds ratio $=1 \cdot 33 ; 95 \%$ CI $0 \cdot 96,1 \cdot 84$, cases compared with hospital controls).

Conclusions - The findings suggest that it is not where the child defecates that matters but how the mother then deals with the child's stools.

( $\mathcal{F}$ Epidemiol Community Health 1994;48:270-275)

Diarrhoea control programmes have historically focussed largely on effective treatment with oral rehydration (ORT). It has been recognised for some time, however, that the impact of ORT on diarrhoea mortality is, necessarily, limited and that its impact on diarrhoea morbidity may be small. ${ }^{1}$ The authors of a recent review concluded that an immediate priority is the "vigorous implementation of the available cost-effective preventive interventions". 2 Programmes to improve hygiene practices represent one such intervention. ${ }^{23} \mathrm{~A}$ wide range of behaviours is covered by the term "hygiene practices". Programmes which aim to improve these will have to focus on a small number of behaviours. These targeted behaviours will have to be chosen on the basis of their prevalence in the community, their amenability to change, and the epidemiological evidence of their impact on diarrhoea rates. Some evidence of links between behaviours surrounding stool disposal and childhood diarrhoea is now beginning to emerge, particularly from three studies from Asia. ${ }^{4-6}$

In an urban setting in West Africa, we carried out a study to identify interventions that might reduce early childhood morbidity from diarrhoea using a wide range of techniques. In this paper we present that component of the study which concerned the association between child defecation behaviour, mothers' stool disposal practices, visible faecal contamination of the environment, and the rate of admission to hospital of young children with symptoms of diarrhoea or dysentery, or both. Other findings from the study, including detailed descriptions of the setting and of mothers' beliefs and practices regarding diarrhoea and stool hygiene, have been presented elsewhere. ${ }^{78}$

\section{Methods}

A case-control study was conducted over a period of 15 months in 1990 and 1991 in the town of Bobo-Dioulasso, Burkina Faso. The town has a third of a million inhabitants of mixed ethnic origin. Residential zones are divided into rectangular compounds. A typical compound might have up to 10 single storeyed, mud walled houses surrounding a central communal earth floored yard where most domestic activity takes place. A compound may house one extended family, or several families renting houses, or a mixture of both. Nine out of 10 compounds have a pit latrine, about one third have a communal tap, one third fetch water from standpipes, and one third use private or communal wells.

During the period of the study an effort was made to enrol all children aged 36 months or less, and resident in the town of Bobo-Dioulasso, who were admitted to the paediatric 
department of the Sanou Souro Regional Hospital. All children were examined by a doctor who filled in a clinical form recording signs and symptoms on admission (reported by the mother or observed by the physician), duration of the illness, and information on treatment-seeking behaviour before coming to the hospital. The height and weight of the child were also measured at the time of admission. Stool samples and rectal swabs were collected and other laboratory tests were performed as appropriate. At hospital discharge the primary and secondary diagnoses were recorded, taking account of the laboratory findings and the child's clinical file. After discharge the child was visited at home, whenever possible, by one of five female fieldworkers, who conducted a detailed interview with the mother. In particular, the mother was asked questions concerning the child's defecation behaviour and how the child's stools were disposed of. Before leaving, the fieldworker made spot observations of environmental conditions in and around the courtyard.

Following a set of predetermined rules, the interviewer then selected a child of roughly similar age to the hospital case from among the neighbours of the case. (The interviewer turned left on leaving the compound of the case, then entered the second compound on the left and, visiting houses in clockwise order, recruited the first child within six months of the age of the case as neighbourhood control if the parents gave their consent. If no such child was identified the interviewer continued along the street.) Similar interviews and spot observations were then performed for the neighbouring child. Thus, interviewers were aware of whether or not the child had been admitted to hospital, but they were not told the child's symptoms. In addition, structured observations of hygiene behaviours were conducted in the households of a subsample of cases and controls.

GROUPS

For the purposes of the following analyses three groups of children were identified:

Cases

Any child aged 36 months or less, resident in Bobo-Dioulasso and admitted to hospital at Sanou Souro Hospital during the period of the study, with symptoms which included diarrhoea or dysentery, or both, as reported by the mother.

\section{Neighbourhood controls}

These were neighbours of children admitted to hospital with symptoms of diarrhoea or dysentery, or both, matched for age group.

\section{Hospital controls}

Any child aged 36 months or less, resident in Bobo-Dioulasso and admitted to hospital at
Sanou Souro Hospital during the period of the study without symptoms of diarrhoea or dysentery.

\section{DATA ANALYSIS}

Data were double-entered onto a microcomputer in Bobo-Dioulasso. Analyses were performed using the computer packages Epi Info, Version 5 and EGRET. For the comparison of cases with neighbourhood controls, the pair matching was retained in the analysis by the use of conditional logistic regression analysis. ${ }^{9}$ For the comparison of cases with hospital controls, unmatched techniques including stratification and logistic regression analysis controlling for time and location of household were used. The confidence intervals quoted were estimated using the method of maximum likelihood. Controls were recruited concurrently with the cases and therefore the odds ratios obtained provide estimates of the rate ratio for admission to hospital with diarrhoea or dysentery, or both. ${ }^{10}$

\section{Results}

Between 15 January 1990 and 31 March 1991, 1056 children aged 0 to 36 months were admitted to hospital with symptoms that included diarrhoea or dysentery (bloody or mucoid stools), or both. Table 1 presents the age and sex distribution of these children together with clinical signs and symptoms associated with the illness. The incidence of hospital admission with diarrhoea or dysentery was highest in children aged 6 to 11 months and was higher in boys than girls. Signs and symptoms most commonly associated with diarrhoea/dysentery were dehydration $(61 \%)$, fever $(61 \%)$, and vomiting $(61 \%)$.

Table 1 Distribution of 1056 children admitted to hospital with signs of diarrhoea or dysentery with regard to age, sex, and various aspects of the illness

\begin{tabular}{|c|c|}
\hline & $\begin{array}{l}\text { No }(\%) \\
\text { children }\end{array}$ \\
\hline \multicolumn{2}{|l|}{ Age: } \\
\hline \multirow{2}{*}{$\begin{array}{l}0-5 \text { months } \\
\text { 6-11 months }\end{array}$} & $163(15)$ \\
\hline & $335(32)$ \\
\hline 12-17 months & $233(22)$ \\
\hline \multirow{2}{*}{$\begin{array}{l}18-23 \text { months } \\
24-36 \text { months }\end{array}$} & $153(14)$ \\
\hline & $172(16)$ \\
\hline \multicolumn{2}{|l|}{ Sex: } \\
\hline $\begin{array}{l}\text { Sex: } \\
\text { Male }\end{array}$ & $583(55)$ \\
\hline $\begin{array}{l}\text { Female } \\
\text { puration the illness hefore }\end{array}$ & $473(45)$ \\
\hline \multicolumn{2}{|l|}{$\begin{array}{l}\text { Duration of the illness before } \\
\text { hospitalisation: }\end{array}$} \\
\hline 0 days & $45(4)$ \\
\hline $\begin{array}{l}1 \text { day } \\
2-3 \text { davs }\end{array}$ & $84(8)$ \\
\hline \multirow{2}{*}{ 4-7 days } & $206(20)$ \\
\hline & $273(26)$ \\
\hline 8-14 days & $131(12)$ \\
\hline $\begin{array}{l}\text { More than } 14 \text { days } \\
\text { Signs and symptoms. }\end{array}$ & $310(30)$ \\
\hline \multicolumn{2}{|l|}{ Signs and symptoms: } \\
\hline \multirow{3}{*}{$\begin{array}{l}\text { Diarrhoea without dysentery } \\
\text { Dysentery without diarrhoea } \\
\text { Diarrhoea with dysentery }\end{array}$} & $474(45)$ \\
\hline & $91(9)$ \\
\hline & $491(46)$ \\
\hline $\begin{array}{ll}\text { Dyspnoea: } & \begin{array}{l}\text { Yes } \\
\text { No }\end{array}\end{array}$ & $\begin{array}{l}343(33) \\
693(67)\end{array}$ \\
\hline \multirow{2}{*}{$\begin{array}{ll}\text { Fever: } & \text { Yes } \\
& \text { No }\end{array}$} & $637(61)$ \\
\hline & 411 (39) \\
\hline \multirow{2}{*}{$\begin{array}{r}\text { Malnutrition: Yes } \\
\text { No }\end{array}$} & 359 (35) \\
\hline & $681(65)$ \\
\hline \multirow{5}{*}{$\begin{array}{ll}\text { Vomiting: } & \text { Yes } \\
\text { Dehydration: } & \begin{array}{l}\text { No } \\
\text { Mild/moderate } \\
\text { Severe }\end{array} \\
& \\
\end{array}$} & $638(61)$ \\
\hline & 406 (39) \\
\hline & $402(39)$ \\
\hline & $485(47)$ \\
\hline & $150(14)$ \\
\hline
\end{tabular}


A total of 2793 home interviews with mothers of young children (757 children in hospital with diarrhoea or dysentery, 631 children in hospital without diarrhoea or dysentery, and 1405 neighbours of hospitalised children) were completed. Thus, for the diarrhoea cases a follow up rate of $72 \%$ was achieved. The same rate of follow up $(72 \%)$ was achieved for children admitted to hospital without diarrhoea. Of the 299 diarrhoea cases who were not followed up at home - 160 left the hospital before contact was established with the home interview team (139 of these children spent less than 24 hours at the hospital); the mothers of 23 children refused to take part in the study; 13 were children who were not resident in the town or who were too old; and 103 were not followed up because of temporary shortages of field staff. The rate of follow up was strongly associated with the outcome of hospital admission; whether the child was discharged alive, left without being discharged, or died in hospital $(\mathrm{p}<0.001)$. Of those children who died, only $42 \%$ were followed up at home, while of those who were discharged, $80 \%$ were followed up. After taking account of the outcome of admission to hospital, the only factors which remained significantly associated with a reduced rate of follow up were the presence of fever $(p<0.01)$ and the degree of dehydration $(\mathrm{p}=0.01)$.

Mothers' responses to the questions "where does your child defecate?" and "how do you dispose of your child's stools?" varied with the

Table 2 Distribution of children admitted to hospital with diarrhoea/dysentery, their neighbourhood controls, and children hospitalised without diarrhoea/dysentery with regard to demographic, socioeconomic, and cultural factors

\begin{tabular}{|c|c|c|c|}
\hline Factor & $\begin{array}{l}\text { Children } \\
\text { hospitalised } \\
\text { with diarrhoea }\end{array}$ & $\begin{array}{l}\text { Neighbourhood } \\
\text { controls }\end{array}$ & $\begin{array}{l}\text { Children } \\
\text { hospitalised } \\
\text { without diarrhoea }\end{array}$ \\
\hline \multicolumn{4}{|l|}{ Age in months: } \\
\hline $0-5$ & $113(15)$ & $132(17)$ & $119(19)$ \\
\hline $6-11$ & $256(34)$ & $224(30)$ & $132(21)$ \\
\hline $12-17$ & $168(22)$ & $177(23)$ & $113(18)$ \\
\hline $18-23$ & $111(15)$ & $106(14)$ & $99(16)$ \\
\hline $24-36$ & $109(14)$ & $118(16)$ & $167(27)$ \\
\hline \multicolumn{4}{|c|}{ 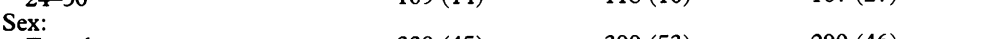 } \\
\hline Female & $339(45)$ & 399 (53) & $290(46)$ \\
\hline Male & $418(55)$ & $358(47)$ & $340(54)$ \\
\hline \multicolumn{4}{|c|}{ Mother's religion: } \\
\hline Muslim & $585(77)$ & $585(77)$ & $477(76)$ \\
\hline Christian & $168(22)$ & $159(21)$ & $148(23)$ \\
\hline Animist & $3(0)$ & $12(2)$ & $5(1)$ \\
\hline \multicolumn{4}{|c|}{ Mother's ethnic group: } \\
\hline Mossi & $194(26)$ & $199(26)$ & $177(28)$ \\
\hline From Bobo & $428(57)$ & $433(57)$ & $337(54)$ \\
\hline Other & $135(18)$ & $125(17)$ & $116(18)$ \\
\hline \multicolumn{4}{|c|}{ Father's occupation: } \\
\hline Regular & $493(65)$ & $481(64)$ & $436(70)$ \\
\hline Irregular & $171(23)$ & $187(25)$ & $119(19)$ \\
\hline Farmer & $87(12)$ & $86(11)$ & $68(11)$ \\
\hline \multicolumn{4}{|l|}{ Electricity: } \\
\hline Yes & $240(32)$ & $244(32)$ & $190(30)$ \\
\hline No & $515(68)$ & $513(68)$ & $438(70)$ \\
\hline \multicolumn{4}{|r|}{ (n) } \\
\hline Yes & $481(64)$ & $478(63)$ & $405(64)$ \\
\hline No & $273(36)$ & $278(37)$ & $225(36)$ \\
\hline \multicolumn{4}{|c|}{ Mother's education: } \\
\hline None & $467(62)$ & $477(63)$ & $404(64)$ \\
\hline Primary & $186(25)$ & $191(25)$ & $135(21)$ \\
\hline Secondary & $100(13)$ & $89(12)$ & $89(14)$ \\
\hline \multicolumn{4}{|l|}{ Water source: } \\
\hline Tap in yard & $220(29)$ & $216(29)$ & $193(31)$ \\
\hline Tap outside & $18(2)$ & $23(3)$ & $17(3)$ \\
\hline Public tap & $241(32)$ & $228(30)$ & $219(35)$ \\
\hline Well in yard & $189(25)$ & $194(26)$ & $135(21)$ \\
\hline Well outside & $76(10)$ & $78(10)$ & $50(8)$ \\
\hline Stream & $12(2)$ & $15(2)$ & $14(2)$ \\
\hline \multicolumn{4}{|l|}{ Latrine/WC: } \\
\hline Yes & $672(89)$ & $675(89)$ & $556(88)$ \\
\hline No & $83(11)$ & $81(11)$ & $73(12)$ \\
\hline
\end{tabular}

age of the child. For children aged less than 6 months, $52 \%$ were reported to defecate in a wrapper (length of cotton cloth). Among mothers of children aged 6 months or more, over $80 \%$ reported that the child used a pot. Above 6 months of age, a small proportion of children $(8 \%)$ were reported to defecate on the ground inside the yard. The percentage of mothers who reported the use of a latrine to dispose of child stools rose from $38 \%$ of mothers of children aged less than 6 months to $76 \%$ of mothers of children aged 12 months or more. Overall, most mothers $(63 \%)$ reported that their child defecated in a pot and that they then disposed of the child's stools in the latrine. Latrines were present in $89 \%$ of compounds.

Human stools were observed in $374(13 \%)$ of all yards visited. The visibility of human stools was not strongly associated with the age of the child $\left(\chi^{2}=8.35 ; 4 \mathrm{df} ; \mathrm{p}=0.08\right)$. Human stools were most frequently observed in yards where mothers reported that the child defecated in the yard $(24 \%)$ and least often observed in yards where mothers reported that the child used a pot $(12 \%)\left(\chi^{2}=21.6 ; 3 \mathrm{df}\right.$; $\mathrm{p}<0.0001)$. Human stools were more frequently observed in yards where the mother reported disposing of the child's stools in the yard $(22 \%)$ and least often observed when she reported disposing of the stools in the latrine $(11 \%)\left(\chi^{2}=35 \cdot 7 ; 2\right.$ df; $\left.p<0.0001\right)$.

Children admitted to hospital with symptoms of diarrhoea or dysentery were compared with two reference groups - their neighbourhood controls and children hospitalised without diarrhoea or dysentery. Table 2 shows the distribution of these three groups of children with regard to a number of demographic, socioeconomic, and cultural factors. Diarrhoea cases were similar to their neighbourhood controls with regard to their age, ethnic and religious backgrounds, and the socioeconomic status of their households. They differed from their neighbourhood controls with regard to their sex distribution $(55 \%$ of diarrhoea cases were male versus $47 \%$ of neighbourhood controls, $\mathrm{p}=0.002$ ). Diarrhoea cases were similar to children admitted to hospital without symptoms of diarrhoea or dysentery with regard to their sex, ethnic and religious backgrounds, and the socioeconomic status of their households. Diarrhoea cases differed from hospitalised children without diarrhoea with regard to their age distribution: $34 \%$ of diarrhoea cases were aged 6-11 months compared with $21 \%$ of children without diarrhoea, while $14 \%$ of diarrhoea cases were aged 24-36 months compared with $27 \%$ of children without diarrhoea $(\mathrm{p}<0.001)$.

Table 3 presents a comparison of diarrhoea cases with each of the two reference groups with regard to defecation and stool disposal practices, and with regard to the observation of stools in the yard. Mothers of diarrhoea cases were more likely than both mothers of neighbourhood controls and mothers of hospitalised children to report disposing of the child's stools elsewhere than in the latrine, although the magnitude of this association was relatively 
Table 3 Distribution of diarrhoea cases, their community controls, and children admitted to hospital without diarrhoea with regard to child defecation and stool disposal practices

\begin{tabular}{|c|c|c|c|c|c|}
\hline Factor & $\begin{array}{l}\text { Cases of } \\
\text { diarrhoea }\end{array}$ & $\begin{array}{l}\text { Neighbourhood } \\
\text { controls }\end{array}$ & $\begin{array}{l}\text { Odds ratio* } \\
(95 \% \text { CI })\end{array}$ & $\begin{array}{l}\text { Hospital controls } \\
\text { without diarrhoea }\end{array}$ & $\begin{array}{l}\text { Odds† ratio } \\
(95 \% \text { CI })\end{array}$ \\
\hline \multicolumn{6}{|c|}{ Where does child defecate?: } \\
\hline Pot/latrine & $554(74)$ & $573(76)$ & 1.00 & $452(72)$ & 1.00 \\
\hline Elsewhere & $200(26)$ & $184(24)$ & $\begin{array}{l}1.21 \\
(0.92,1.58)\end{array}$ & $175(28)$ & $\begin{array}{l}1 \cdot 02 \\
(0 \cdot 78,1 \cdot 34)\end{array}$ \\
\hline \multicolumn{6}{|l|}{ Stool disposal: } \\
\hline Latrine & $488(65)$ & $519(69)$ & 1.00 & $417(67)$ & 1.00 \\
\hline Elsewhere & $267(35)$ & $238(31)$ & $\begin{array}{l}1 \cdot 31 \\
(1.02,1 \cdot 69)\end{array}$ & $210(33)$ & $\begin{array}{l}1 \cdot 20 \\
(0.93,1.54)\end{array}$ \\
\hline \multicolumn{6}{|c|}{ Stools visible in yard: } \\
\hline & $627(83)$ & $651(86)$ & 1.00 & $549(87)$ & 1.00 \\
\hline Yes & $127(17)$ & $103(14)$ & $\begin{array}{l}1.44 \\
(1.03,2.03)\end{array}$ & $80(13)$ & $\begin{array}{l}1.43 \\
(1.04,1.97)\end{array}$ \\
\hline
\end{tabular}

* Estimated using conditional logistic regression to retain case-control matching and controlling

age. residence. children with diarrhoea or dysentery. Similar comparisons also suggest that the presence of visible human stools in the yard may be associated with an increase in the rate of hospital admission with diarrhoea of about $35 \%$. The confidence intervals around most of these estimates are, however, wide and several include the null value $(1 \cdot 0)$.

\section{Discussion}

Our results suggest that where children under 37 months of age (are reported to) defecate is not associated with their rate of hospital admission with diarrhoea or dysentery, or both. Where the mother disposes of the child's stools, on the other hand, may be. One hypothesis which would explain these findings may be stated as follows: it is not where the child defecates that is important, it is what the mother does with the faeces afterwards that counts. This hypothesis seems biologically plausible.

On the other hand, the associations that we have observed between stool disposal practices, faecal contamination of the yard, and hospital admission with diarrhoea or dysentery may not be causal but due to bias. Among the possible biases are recall bias on the part of the mother, bias on the part of the interviewer, selection bias, and confounding.

Recall bias on the part of the mother might have arisen if, for example, mothers of children in the case group were more likely to over-report the use of a latrine than mothers of children in the control groups. We found no evidence of such differential misclassification when we compared questionnaire data and data obtained by structured observations, though this finding is from a subsample of only 240 children.

Bias could also have arisen if interviewers knew who was a case and who a control and this influenced the way in which they administered the questionnaire. In this study interviewers knew if children had been admitted to hospital or not, but they were not told whether hospitalised children had been suffering from diarrhoea. Thus, though interviewer bias might explain the associations observed when cases are compared with neighbourhood controls, it was unlikely to have been responsible for the associations observed when cases were compared with hospitalised controls.

If cases and controls differed in their use of government health services in general, and the hospital in particular, then the observed associations may have arisen through selection bias. We have some evidence to support the contention that cases and controls use government facilities to a similar extent. In our analyses we have used both hospital and neighbourhood controls. The consistency between the findings with each of the two control groups provides some circumstantial evidence against selection bias as the explanation for the observed associations. In addition, the three groups had all had a similar degree of contact with government vaccination services $-85 \%$ of cases had vaccination cards, while the percent- latrine may be associated with a $30-50 \%$ increase in the rate of admission to hospital of 
Table 4 Results of logistic regression analyses (conditional and unconditional) to examine the association between reported child defecation behaviour, reported stool disposal practices of the mother, visibility of stools in the yard, and risk of admission to hospital with symptoms of diarrhoea or dysentery, or both

\begin{tabular}{|c|c|c|c|c|}
\hline $\begin{array}{l}\text { Reference } \\
\text { group }\end{array}$ & Analysis & $\begin{array}{l}\text { Risk } \\
\text { factor(s) }\end{array}$ & & $\begin{array}{l}\text { Odds }(95 \% \mathrm{CI}) \\
\text { ratio }\end{array}$ \\
\hline Neighbourhood* & Conditional & $\begin{array}{l}\text { Defecation } \\
\text { behaviour } \\
\text { Stool } \\
\text { disposal }\end{array}$ & $\begin{array}{l}\text { Pot/latrine } \\
\text { Elsewhere } \\
\text { Latrine } \\
\text { Elsewhere }\end{array}$ & $\begin{array}{l}1 \cdot 00 \\
1 \cdot 10(0 \cdot 78,1 \cdot 57) \\
1 \cdot 00 \\
1 \cdot 50(1 \cdot 09,2 \cdot 06)\end{array}$ \\
\hline Neighbourhood $\dagger$ & Conditional & $\begin{array}{l}\text { Visibility } \\
\text { of stools }\end{array}$ & $\begin{array}{l}\text { No } \\
\text { Yes }\end{array}$ & $\begin{array}{l}1.00 \\
1.38(0.98,1.95)\end{array}$ \\
\hline $\begin{array}{l}\text { Hospital }+ \\
\text { children } \\
\text { without } \\
\text { diarrhoea }\end{array}$ & Unconditional & $\begin{array}{l}\text { Defecation } \\
\text { behaviour } \\
\text { Stool } \\
\text { disposal }\end{array}$ & $\begin{array}{l}\text { Pot/latrine } \\
\text { Elsewhere } \\
\text { Latrine } \\
\text { Elsewhere }\end{array}$ & $\begin{array}{l}1 \cdot 00 \\
0.84(0 \cdot 60,1 \cdot 18) \\
1.00 \\
1 \cdot 31(0 \cdot 96,1 \cdot 79)\end{array}$ \\
\hline $\begin{array}{l}\text { Hospital§ } \\
\text { children } \\
\text { without } \\
\text { diarrhoea }\end{array}$ & Unconditional & $\begin{array}{l}\text { Visibility } \\
\text { of stools }\end{array}$ & $\begin{array}{l}\text { No } \\
\text { Yes }\end{array}$ & $\begin{array}{l}1.00 \\
1.33(0.96,1.84)\end{array}$ \\
\hline
\end{tabular}

* Confounders retained in the model: age, mother's religion, father's occupation, source of drinking water, possession of a radio-cassette, whether the child was reported to eat soil, whether the mother practised "lavements" (anal purging) on the child, number of people in the household

+ Confounders retained in the model: age, whether the mother practised "gavages" (force feeding herbal remedies) on the child.

$\ddagger$ Confounders retained in the model: age, period of recruitment, area of residence, ethnic origin of the mother.

$\$$ Confounders retained in the model: age, period of recruitment, area of residence, father's occupation, presence of stagnant water in the yard.

age with vaccination cards in each of the control groups was $87 \%$.

Having made home visits to only $72 \%$ of the children recruited in the hospital, we cannot be sure that findings would have been similar had all children been followed up. Though a higher proportion of children who were not visited at home died in hospital, had fever, or had severe dehydration than those who were followed up, we can see no reason to suppose that follow up was differential with respect to exposure status in the case-hospital control comparison. Hence, it seems unlikely that the associations observed were due to such selection effects.

We cannot exclude the possibility that the positive associations that we have observed arose through confounding. Children admitted to hospital were similar to their neighbourhood controls with regard to a wide range of socioeconomic indicators which we recorded. We therefore think it is unlikely that socioeconomic confounding could explain the observed association. The way in which a mother disposes of her child's stools may, however, be closely correlated with a range of other behaviours which were not recorded in this study. Stool disposal behaviour may thus be acting as a proxy for other behaviours (for example, food hygiene, handwashing, disposal of stools of other children) which are the real risk factors for admission to hospital with diarrhoea. It is also possible that hygiene practices are markers for some unmeasured factors such as the attitude of a mother to her child, and the priority which she assigns to childcare. Such factors might intervene by other routes to protect or put a child at risk from severe diarrhoea. Further work to investigate other hygiene behaviours and the correlation between these and maternal attitudes would help to clarify this point. Poor stool disposal practices and visible human faecal material in the yard are, however, both plausible risk factors for hospital admission with diarrhoea.
Finally, it is possible that these findings arose through chance alone; almost all the confidence intervals around our estimates of the odds ratios in the final models include 1.0 . Only one of the associations is statistically significant at the $5 \%$ level, the other associations are "borderline" $(0.05<p<0 \cdot 10)$. The consistency across control groups of the findings with regard to stool disposal and stool visibility lends some support to our belief that the observed associations are not chance findings. Indeed, it may be that the odds ratios we have obtained substantially underestimate the true associations between the stool disposal behaviour of the mother and the presence of stools in the yard and the rate of hospital admission with diarrhoea. We have shown elsewhere $^{7}$ that variation in behaviours, or observed environmental conditions from one day to the next, can result in a serious underestimate of the true odds ratio.

Our findings with regard to stool disposal are broadly consistent with those of a casecontrol study conducted in the Philippines. ${ }^{4}$ These authors distinguished three methods of stool disposal (when the child defecated in a nappy); throwing the faeces "away with the washing", disposal in a latrine, and other (throwing in the yard, river, etc). Relative to children in the "other" category, those whose mothers disposed of the faeces in the latrine had a rate of diarrhoea reduced by about $40 \%$. The confidence interval around this estimate was, however, wide, ranging from a reduction of $70 \%$ to an increase of $13 \%$. Bukenya and Nwokolo, ${ }^{5}$ reporting a longitudinal study from Papua, New Guinea of children aged less than 5 years, found the presence of faeces (human or animal) in the yard to be associated with a $48 \%$ increase in the rate of diarrhoea. They observed "no meaningful association" between the method of removal of children's faeces from the yard and diarrhoea rates. These data are not, however, presented, so we cannot assess the degree of heterogeneity of stool disposal practices in this community nor the power of the study to detect any such association should it exist. In Sri Lanka, Mertens et $a l^{6}$ observed that failure to dispose of children's faeces in a latrine was associated with an increased incidence of diarrhoea of about $40 \%$.

In summary, we found no evidence to suggest that where a child defecates is associated with that child's rate of admission to hospital with symptoms of diarrhoea or dysentery, or both, but sorre evidence linking the rate of hospital admission with both what the mother does with the child's stools and whether human stools were visible in the family's yard. One possible explanation for these findings is that it is not so much where the child defecates that matters as how the mother then deals with the stools.

The study was a collaboration between the Ministry of Health, Burkina Faso (Paediatric Department, Bobo-Dioulasso), the London School of Hygiene and Tropical Medicine, United Kingdom, Centre Muraz (Organisation de Cooperation et de Coordination pour la lutte contre les Grandes Endemies), Burkina Faso, and University of Bordeaux II, France. The 
study was supported primarily by the "Science and Technology for Development Programme of the European Community", contract TS-2-M-0087, UK. The authors also than UNICEF, Ouagadougou, the Ministry of Health, Burkina Faso, and the Overseas Development Administration of the United Kingdom for their financial contributions. Special thanks are due to the Provincial Director of Health, Houet, to the team of the DESA, Bobo-Dioulasso, the team at the Paediatric Department, Sanou Souro Hospital, Bobo-Dioulasso, and the team at the biology laboratory, Centre Muraz.

1 Feachem RG. Preventing diarrhoea: what are the policy options? Health Policy and Planning 1986;1:109-17.

2 Martines J, Phillips M, Feachem RGA. Health sector priorities review: diarrheal disease. Washington: The World ties review: diarrheal dised
Bank (HSPR-21), 1991

3 Feachem RG. Interventions for the control of diarrhoeal diseases among young children: promotion of personal and domestic hygiene. Bull WHO 1984:62:467-76.

4 Baltazar JC, Solon FS. Disposal of faeces of children under two years old and diarrhoea incidence: a case-control study. Int $\mathcal{F}$ Epidemiol 1989;18(Suppl 2):S16-S19.

5 Bukenya GB, Nwokolo N. Compound hygiene, presence of standpipe and the risk of childhood diarrhoea in an urban settlement of Papua New Guinea. Int $f$ Epidemiol 1991;20:534-9.

6 Mertens TE, Jaffar S, Fernando MA, Cousens SN, Feachem RG. Excreta disposal and latrine ownership in relation to childhood diarrhoea in Sri Lanka. Int f Epidemiol 1992;21(6):1157-64

7 Curtis V, Cousens SN, Mertens TE, Traoré E, Kanki B, Diallo I. Structured observations of hygiene practices in Burkina Faso: validity, variability and utility. Bull WHO 1993;71(1):23-32.

8 Cousens S, Nacro B, Curtis V, et al. Prolonged breast feeding is not associated with an increased risk of malnutrition in Burkina Faso. Bull WHO. 1993;71(6):713-22.

9 Breslow NE, Day NE. Statistical methods in cancer research. Volume I. The analysis of case-control studies. Lyon: IARC Scientific Publications, 1980.

10 Miettinen O. Estimability and estimation in case-referent studies. Am $\mathcal{F}$ Epidemiol 1976;103:226-35. 